\section{Microbiological and chemico-physical shelf-life and panel test to evaluate acceptability of liver mortadella}

\author{
Erica Tirloni, Simone Stella, Cristian \\ Bernardi, Vittorio Maria Moretti, Carla \\ Bersani, Patrizia Cattaneo \\ Department of Health, Animal Science \\ and Food Safety, University of Milan, \\ Milan, Italy
}

\section{Abstract}

This study aimed to evaluate the shelf life of sliced cooked liver mortadella packaged in MAP (70-85\% $\mathrm{N}_{2}, 15-30 \% \mathrm{CO}_{2}$ ) and stored in refrigeration $\left(4^{\circ} \mathrm{C}\right)$ or slight thermal abuse $\left(8^{\circ} \mathrm{C}\right)$ for up to 49 days (declared best before date 45 days). The proximate composition, aw nitrites and $\mathrm{NaCl}$ content were determined at T0. Weekly, samples were submitted to microbiological [total viable count (TVC), lactic acid bacteria (LAB), Enterobacteriaceae, Escherichia coli, Pseudomonas spp., coagulase positive staphylococci, sulphite reducing clostridia, yeasts and moulds, Listeria monocytogenes and Salmonella spp.] and physicalchemical analyses [ $\mathrm{pH}$, colorimetric parameters, total volatile basic nitrogen (TVBN), thiobarbituric acid reactive substances (TBARs)], in parallel with consumer acceptability tests. The product characteristics (low salt and nitrites concentration, high aw and $\mathrm{pH}$ close to 6.5) were not efficient hurdles for microbial growth. No pathogens were detected in the samples; the initial TVC [5.4 Log colony forming unit (CFU)/g] increased rapidly, reaching values around $8 \mathrm{Log} \mathrm{CFU} / \mathrm{g}$ at T14 for both the series, and was almost totally composed by $\mathrm{LAB}$, leading to the acidification of the product $\left(\mathrm{pH}\right.$ at $\mathrm{T} 49=5.05$ at $4^{\circ} \mathrm{C}$ and 5.24 at $8^{\circ} \mathrm{C}$ ). The other microbiological parameters were below 2 Log CFU/g. The product showed a good protein and lipid stability (TVBN $<33 \mathrm{~N} / 100 \mathrm{~g}$ and TBARs $<8 \mathrm{nmol} / \mathrm{g}$ at T49). The sensorial quality of liver mortadella was more affected by the storage time than by the temperature. An evident colour modification was detected after T35, when the product was also frequently rejected by the panellists, mainly due to odour. Thus, the shelf life of sliced cooked liver mortadella should be shortened below 30 days.

\section{Introduction}

Liver mortadella is a ready-to-eat cooked sausage very popular in Northern Italy (mainly Lombardy, Aosta Valley Region and Piedmont) and many other countries (e.g. Germany, France, Switzerland; Villa, 2010). As reported by Cantoni et al. (1974), liver mortadella is obtained starting from dough made of pork meat with the addition of pork liver. The amount of liver added varies depending on the manufacturer, from $2-5 \%$ up to $15-25 \%$. Depending on the proportion of liver used, the flavour of the product is more or less intense. In the production process, the ground meat and the fat are mixed coarsely, while the liver is finely cut separately. Pork rind, salt, spices, flavourings and binders could be also supplemented during the preparation. The resulting mixture is stuffed into natural or artificial casings. In fact, there are two variants of the liver mortadella: a raw version and a cooked one. Typically, the artificial casing is used in the cooked variant, while the natural for both the typologies.

This product contains high levels of fat and iron: as already reported for other liver products like pâté, a development of lipid and protein oxidation during refrigerated storage could lead to the degradation of the heme molecule and the release of iron, reducing the oxidative stability (Estévez et al., 2004), thus resulting in unacceptable products.

From a microbiological point of view, the chemico-physical characteristics typical of liver mortadella such as low salt content, high $\mathrm{pH}$ value and high water activity $\left(\mathrm{a}_{\mathrm{w}}\right)$, are singularly only small hurdles that are not able to inhibit the bacteria commonly associated with these products. Generally, the prevalent microflora present after production is lactic acid bacteria (von Holy et al., 1991), but their number is too low to contrast the potentially pathogenic bacteria (e.g. Listeria monocytogenes, Salmonella spp., coagulase positive staphylococci) that could be transmitted through contaminated processing environment, instruments and manipulation by the operators. This aspect should be carefully considered since these products are very often handmade or processed in small factories (Paleari et al., 2005).

Although it is very appreciated by consumers, a small number of scientific papers concerning liver mortadella has been published (Cantoni et al., 1974; Paleari et al., 2005), and no analytical data relating to the behaviour of the product during its shelf life are available.

Thus, the aim of the present study was to evaluate the shelf-life of sliced cooked liver mortadella, pre-packaged in modified atmosphere (MAP) and maintained at refrigerated conditions $\left(4^{\circ} \mathrm{C}\right)$ and in thermal abuse $\left(8^{\circ} \mathrm{C}\right)$; chemical-physical and microbiological parameters were considered in order to outline the changes during the shelf-life and to evaluate the suitability for consumption. A panel test was also evaluated in order to highlight the sensorial acceptability of the product.
Correspondence: Erica Tirloni, Department of Health, Animal Science and Food Safety, University of Milan, via Celoria 10, 20133, Milan, Italy.

Tel: +39.02 .50317855 - Fax: +39.02 .50317870 .

E-mail: erica.tirloni@unimi.it

Acknowledgements: the authors would like to thank Fumagalli Industria Alimentare S.p.A., Tavernerio (CO), Italy for providing the samples used in this trial. The students Cinzia Ruspi and Mariantonia Vaghi should also be acknowledged for the lab assistance.

Conflict of interest: the authors declare no potential conflict of interest.

Key words: Liver mortadella; Shelf life; 0xidation; Lactic acid bacteria.

Received for publication: 15 July 2016 .

Revision received: 14 October 2016.

Accepted for publication: 14 October 2016.

This work is licensed under a Creative Commons Attribution-NonCommercial 4.0 International License (CC BY-NC 4.0).

(C) Copyright E. Tirloni et al., 2016

Licensee PAGEPress, Italy

Italian Journal of Food Safety 2016; 5:6165

doi:10.4081/ijfs.2016.6165

\section{Materials and Methods}

Ingredients, production and chemical composition of liver mortadella

Liver mortadella samples were produced in a medium scale factory in the North of Italy. The recipe of the product is reported in Table 1. Briefly, raw meat (first-class lean pork) was minced and mixed with pork liver (up to 25\%), fat and an aliquot of water, forming a stable matrix to which other commercial ingredients were added to produce the liver mortadella. All ingredients were mixed for $20 \mathrm{~min}$, and the mixture was then stuffed under vacuum into a synthetic casing. The product was steam cooked at $75^{\circ} \mathrm{C}$ for $8 \mathrm{~h}$ taking care to reach an internal temperature of at least $69^{\circ} \mathrm{C}$. After cooling down in appropriate refrigerated cell, mortadella was sliced in a white chamber and packaged under modified atmosphere $\left(\mathrm{N}_{2}\right.$ from 70 to $85 \%, \mathrm{CO}_{2}$ from 15 to $30 \%$, maximum residue of $\mathrm{O}_{2}<0.4 \%$ ). The best before data assigned by the producer was 45 days. After the production, the samples were immediately transferred to the lab under refrigerated conditions.

\section{Experimental design}

At the lab, the samples were randomly grouped in two series, stored at refrigerated conditions $\left(4^{\circ} \mathrm{C}\right)$ or in thermal abuse $\left(8^{\circ} \mathrm{C}\right)$ 
from T0 (day of the production) to T49 (time after the date by use assigned by the producer that was 45 days). After the production, at T0 the samples were submitted to the following determinations in duplicate: proximate composition (AOAC, 1990), water activity (Rotronic Hygromer Aw-DI0, Basserdorf, Switzerland), nitrites (Mirna and Hohmann, 1969) and salt content as total chlorides (Pearson, 1973). All the determinations were performed in duplicate. At all the settled sampling times $(0,7,14$, $21,28,35,45$ and 49 days from the production) the samples were submitted to microbiological and chemico-physical analyses and panel group's acceptance evaluation.

\section{Microbiological analyses}

For microbial counts, $10 \mathrm{~g}$ of each sample were homogenized in $90 \mathrm{~mL}$ of a diluent solution $(0.85 \% \mathrm{NaCl}$ and $0.1 \%$ tryptone), and serial 10-fold dilutions were prepared. Total viable count (TVC) was determined according to the ISO 4833 (IS0, 2003a) method. Lactic acid bacteria (LAB) were enumerated according to ISO 15214 (IS0, 1998) method. The number of Enterobacteriaceae was determined by the ISO 21528-2 (ISO, 2004) method. Escherichia coli were enumerated according to ISO 16649-2 (IS0, 2001) method. Coagulase-positive Staphylococci were determined by ISO 68881:1999 method (ISO, 1999). The count of spores of sulphite-reducing Clostridia was performed by ISO 15213 (ISO, 2003b) method, after pasteurization of the dilutions. Detection and enumeration of Listeria monocytogenes were performed according to AFNOR methods (AFNOR BRD 07/4-09/98 and AFNOR BRD 07/05-09/01, respectively; AFNOR, 1998). Detection of Salmonella spp. was performed according to ISO 6519 (ISO, 2012). Microbiological analyses were performed in duplicate.

\section{$\mathrm{pH}$ determination}

The $\mathrm{pH}$ of the products was determined by a pHmeter (Ghiaroni, mod. XS pH 6, Buccinasco,
Italy); $5 \mathrm{~g}$ of the product was homogenised with $20 \mathrm{~mL}$ of distilled water and the homogenate immediately subjected to $\mathrm{pH}$ determination in duplicate.

\section{Lipid oxidation}

Thiobarbituric acid reactive substances (TBARS) were determined in duplicate to evaluate the oxidative stability during storage according to Ke et al. (1984) in duplicate for each series.

\section{Total volatile basic nitrogen}

Total volatile basic nitrogen [TVBN; Reg. (EC) N. 2074/2005; European Commission, 2005] was determined on each series in duplicate after sampling for microbiological analyses.

\section{Colour parameters}

Colour parameters were determined on the surface of the slices of liver mortadella using a

Table 1. Recipe of liver mortadella analysed.

\begin{tabular}{lc} 
Ingredients & Quantity (\%) \\
Meat & 94.168 \\
Salt (NaCl) & 3.305 \\
\hline Red wine & 1.309 \\
Sucrose & 0.377 \\
\hline Polyphospahtes & 0.377 \\
Na ascorbate & 0.094 \\
\hline Sodicsal (sodium nitrite 50\%) & 0.009 \\
Grappa & 0.075 \\
\hline Black pepper 1/2 grain & 0.047 \\
White pepper (powder) & 0.094 \\
\hline Lemon & 0.026 \\
Cloves (powder) & 0.005 \\
\hline Cinnamon (powder) & 0.009 \\
Cinnamon & 0.006 \\
\hline Cloves & 0.002 \\
Drugs & 0.009 \\
\hline Total & 100.000 \\
\hline
\end{tabular}

Minolta Chromameter CR-200 (Minolta, Osaka, Japan) working at CIELab system. The $\mathrm{L}^{*}, \mathrm{a}^{*}$ and $\mathrm{b}^{*}$ values, which describe the intenyellowness, respectively, were taken at six locations on the cut surface immediately after opening the pack. Total colour differences $\left(\Delta \mathrm{E}^{*}\right)$ between treated and control samples were calculated as: $\sqrt{ }\left(\mathrm{L}^{*}-\mathrm{L} 2^{*}\right)^{2}+\left(\mathrm{a} 1^{*}-\mathrm{a} 2 *\right)^{2}+$ $\left(\mathrm{b} 1^{*}-\mathrm{b} 2^{*}\right)^{2}$. A $\Delta \mathrm{E}^{*}$ more than 2.3 means a variation hardly perceptible to the human eye, while $\Delta \mathrm{E}^{*}$ more than 3.0 a variation well perceptible to the human eye.

\section{Panel test}

A panel test for the acceptability of liver mortadella maintained at 4 and $8^{\circ} \mathrm{C}$ was tested using a panel composed by 13 members. At all the sampling times, each panellist was presented with two slices of the product for each series and asked the questions: would you eat sity of whiteness/brightness, red colour and

Table 2. Proximate composition, percentage of salt, nitrites, $\mathrm{pH}$ and water activity on day of the production.

\begin{tabular}{lcccc} 
& $\begin{array}{c}\text { Present study } \\
\text { Average } \pm \text { SD }(\mathbf{n = 2})\end{array}$ & $\begin{array}{c}\text { Italian liver mortadella } \\
\text { (Cantoni et al., 1974) } \\
\text { Range }\end{array}$ & $\begin{array}{c}\text { Dutch liver sausages } \\
\text { (Cantoni et al., 1974) } \\
\text { Average }\end{array}$ & $\begin{array}{c}\text { Finnish liver sausages } \\
\text { (Krol, 1966) } \\
\text { Average }\end{array}$ \\
Moisture (\%) & $45.50 \pm 0.09$ & $33.70-36.30$ & 50.96 & 53.30 \\
Proteins (\%) & $14.95 \pm 0.55$ & $14.30-17.70$ & 14.20 & 14.80 \\
\hline Fat (\%) & $36.19 \pm 0.07$ & $39.75-45.33$ & 29.10 & 30.10 \\
Ash (\%) & $3.38 \pm 0.02$ & $6.10-6.50$ & 3.40 & 1.80 \\
\hline Salt (\%) & $2.77 \pm 0.02$ & - & - & 1.90 \\
WPS (\%) & $5.74 \pm 0.08$ & - & - & - \\
\hline Nitrites (ppm) & $12.35 \pm 5.87$ & - & - & - \\
$\mathrm{a}_{\mathrm{w}}$ & $0.952 \pm 0.10$ & - & - & - \\
pH & $6.47 \pm 0.10$ & - & & -
\end{tabular}

SD, standard deviation; WPS, water phase salt; aw, water activity. 
it? If not, which is the reason (colour/odour/both)?

\section{Statistical analysis}

Chemical-physical results obtained during the different sampling time were subjected to statistical analysis through ANOVA test. A probability of $\mathrm{P}<0.05$ was considered as a threshold value for statistically significant differences.

\section{Results}

\section{Chemico-physical characterisation}

The proximate composition determined at T0 is shown in Table 2. The salt and nitrite concentrations, $\mathrm{a}_{\mathrm{w}}$ and $\mathrm{pH}$ of the product are also reported: the observed values (low salt and nitrites concentration, high aw and $\mathrm{pH}$ close to 6.5 ) were not singularly able to inhibit microbial growth.

\section{Evolution of microbial populations and $\mathrm{pH}$ during the shelf life}

In the samples analysed at the two different temperatures, Listeria monocytogenes was always absent in $25 \mathrm{~g}$, as required by Reg. 2073/2005 for ready-to-eat products; also Salmonella spp. was absent in all the samples. High concentrations of total viable count and lactic acid bacteria (LAB) were found since T0 (TVC T0: $5.4 \log$ CFU/g, LAB T0: $3.6 \log$ CFU/g respectively) (Figure 1); generally the presence of microorganisms in a pasteurized meat product could be due to the possible inability of the heating core temperature reached during cooking to eliminate all the microflora present or to a post-contamination occurred during the slicing/packaging process. LAB counts showed a rapid increase (thus representing almost all the total viable count) since T14 at both the two temperatures $\left(4^{\circ} \mathrm{C}\right.$ : $7.9 \pm 0.3 \log \mathrm{CFU} / \mathrm{g}$; $\left.8^{\circ} \mathrm{C}: 8.4 \pm 0.1 \log \mathrm{CFU} / \mathrm{g}\right)$ : these microbial loads could determine a souring of the product during the course of the shelf-life, due to the production of lactic acid. This was also confirmed by the trend observed for $\mathrm{pH}$ values: with the increase of $\mathrm{LAB}$, a constant decrease of $\mathrm{pH}$ values was detected (from T0: 6.47 to T49 $4^{\circ} \mathrm{C}$ : $5.05,8^{\circ} \mathrm{C}$ : 5.24$)$. All the other parameters considered (Enterobacteriaceae, Pseudomonas spp., Escherichia coli, coagulase positive staphylococci, sulphite-reducing clostridia, yeasts and moulds) resulted below the detection limit (2 Log CFU/g).

\section{Lipid oxidation}

Liver mortadella could be prone to lipid oxidation, as it is characterized by high fat and iron content. The level of TBARs was characterized by concentrations below $8 \mathrm{nmol} / \mathrm{g}$ (threshold suggested by Ke et al., 1984) during all the period in both the series, showing a good oxidative stability (Figure 2). This could be possibly due to the presence of antioxidant compounds used as additives in the recipe (e.g. sodium ascorbate, sodium nitrite and polyphosphates) and to the use of $\mathrm{O}_{2}$-free MAP during storage.

\section{Total volatile basic nitrogen}

TVBN content showed a gradual increase from T7, suggesting the occurrence of proteolytic activity related to bacterial growth (Table 3).

\section{Colour parameters}

Considering colour parameters, the samples maintained at $4^{\circ} \mathrm{C}$ were characterized by a sig-

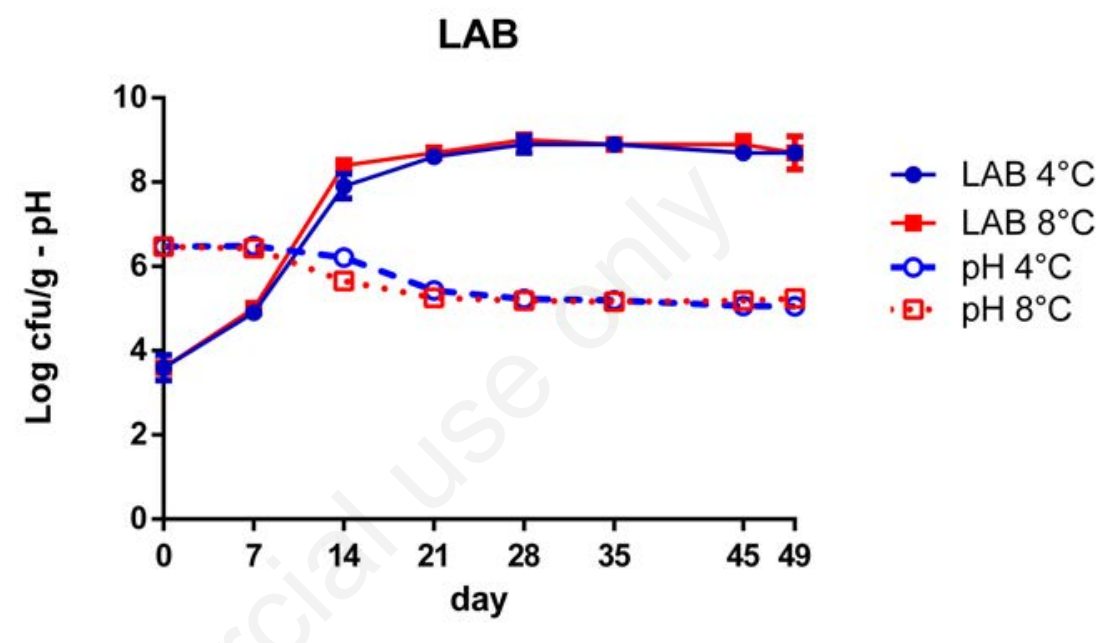

Figure 1. Lactic acid bacteria concentrations and $\mathrm{pH}$.

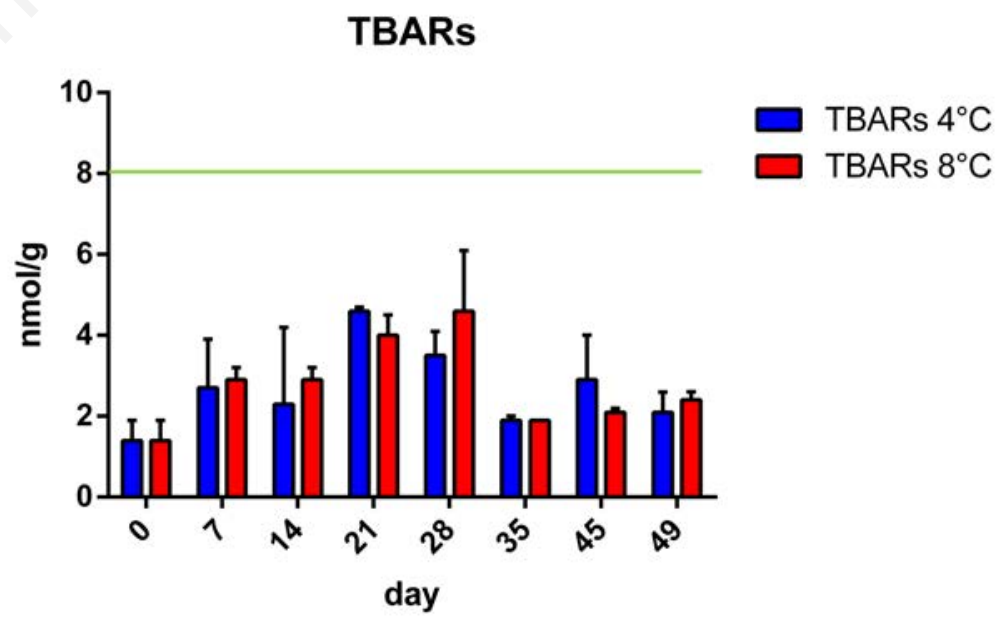

Figure 2. Thiobarbituric acid reactive substances.

Table 3. Total volatile basic nitrogen $(\mathrm{mg} \mathrm{N} / 100 \mathrm{~g})$ detected in the two series during the trial.

\begin{tabular}{|c|c|c|c|c|c|c|c|c|}
\hline & TO & $\mathrm{T7}$ & T14 & $\mathrm{T} 21$ & T28 & T35 & $\mathrm{T} 45$ & $\mathrm{~T} 49$ \\
\hline $4^{\circ} \mathrm{C}$ & $25.00 \pm 4.80$ & $22.78 \pm 2.95$ & $23.82 \pm 0$ & $29.53 \pm 0.07$ & $30.10 \pm 1.50$ & $31.20 \pm 0.40$ & $32.49 \pm 0.3$ & $33.00 \pm 0.20$ \\
\hline $8^{\circ} \mathrm{C}$ & $25.00 \pm 4.80$ & $21.94 \pm 1.00$ & $26.58 \pm 0.30$ & $29.04 \pm 1.05$ & $32.20 \pm 1.10$ & $31.90 \pm 1.10$ & $32.50 \pm 0$ & $30.90 \pm 0.10$ \\
\hline
\end{tabular}


nificantly higher brightness (L) if compared to those maintained at $8^{\circ} \mathrm{C}(\mathrm{P}=0.02)$. No significant differences were detected for the parameters $\mathrm{a}^{*}$ and $\mathrm{b}^{*}(\mathrm{P}=0.15$ and $\mathrm{P}=0.57$, respectively) in the whole period between the two series. Considering the parameter $\Delta \mathrm{E}$, important index used to evidence the chromatic changes perceptible by the eye of consumer, an evident variation of colour was detected at the two temperatures after T35 (Figure 3).

\section{Panel test}

The panel test showed to accept liver mortadella samples maintained at 4 and $8^{\circ} \mathrm{C}$ was constantly high $(>65 \%)$ till T28 in both the series; from T35 a rapid decrease of the acceptability was revealed, with a lower number of acceptable samples if compare to those rejected (data not shown). Considering the reasons for unacceptability of the products, at $4{ }^{\circ} \mathrm{C}$ this was mainly related to the odour (50\%), followed by colour (45\%) and only a little part of the panellist rejected the products due to the changes detected in both colour and odour (5\%). At $8^{\circ} \mathrm{C}$ the odour was responsible for $54 \%$ of the rejections, followed by colour (39\%) and only $7 \%$ indicating both colour and odour as responsible for the unacceptability of the products.

\section{Discussion}

In the present study, the microbiological shelf-life of liver mortadella packaged under MAP was evaluated in optimal refrigerated conditions and in slight thermal abuse. As expected, the microflora that limited the shelflife of this cooked sausage was composed by LAB. The loads of these microorganisms increased rapidly in both the series $\left(4-8^{\circ} \mathrm{C}\right)$ reaching after only 14 days values above $7 \mathrm{Log}$ CFU/g (7.9 and 8.4 Log CFU/g, respectively). Previous studies indicated in 7-8 Log CFU/g the threshold above which consumers generally reject a cooked meat product (Makela and Korkeala, 1987; Borch et al., 1996). In particular, in cooked sausages, LAB should be considered as one of the major components of the microbial population, able to determine, depending on the species present, not only sensory changes (smell, taste) but also visual alterations (e.g. slime onto the surface, gas production) (Korkeala and Björkroth, 1997). As already stated previously for other cooked meat products, also in liver mortadella the presence of high numbers of LAB and the influence on the environment that they colonize during their replication (lactic acid production, acidic $\mathrm{pH}$ ) played a key role due to their positive antimicrobial activity that limits the growth of potentially pathogenic and spoilage microorganisms.

A chemico-physical evaluation was also per- formed considering parameters useful to characterize and highlight the evolution of the product during the storage. The results obtained from the determination of proximate composition, performed at $\mathrm{T} 0$, were compared with the data reported by Cantoni et al. (1974), referred to two different productions, one of cooked liver mortadella produced in Italy and one cooked liver sausage produced in Netherlands and with the data reported by Krol (1966) for Finnish liver sausages. In particular, the data reported by Cantoni et al. (1974), related to Italian cooked liver mortadella, whose percentage of liver employed is not reported, showed lower moisture content while the other parameters were in agreement with those observed in our study. The liver sausages manufactured in Netherlands showed mean values in agreement with ours, except for a lower fat content. Finally, the relative composition of the Finnish liver sausages (Krol, 1966) showed higher moisture content if compared to our products and lower salt content. Moreover, a lower fat content (18.5\%) was revealed in the product studied by Krol (1966). The amount of nitrites in the product was far below the maximum allowed dose of $150 \mathrm{mg} / \mathrm{kg}$ of nitrites (E 249-250), provided for heat-treated meat products.

As described above, due to the presence of a high percentage of fat, the liver mortadella is a product that can be subject to lipid oxidation: the TBARs values indicated substantially an oxidative stability over time. Also TVBN could be considered stable overtime in both the series.

The colour of foodstuffs is one of the most important properties that influence the choice of the consumers at the point of sale: the samples kept at $4^{\circ} \mathrm{C}$ were characterized for the entire trial by a significantly higher brightness index if compared to the samples maintained at $8^{\circ} \mathrm{C}$ while considering the index $\Delta \mathrm{E}$, which expresses the variation of colour over time perceptible from consumers' eye, no differences were detected between samples stored at 4 or $8^{\circ} \mathrm{C}$, with a clear increase of this value only from T45.

The combination of product colour and odour characteristics was considered acceptable by the panel group until 28 days of storage. Considering the answers related to the attribute discriminated, the unacceptability mostly was caused by the odour, especially in thermal abuse, followed by colour. In particular, the product examined was characterized by a peculiar smell, with a very strong aroma, due to the percentage of pork liver in the recipe (25\%), higher if compared to those reported in literature. In fact, starting at T0, this may have affected the acceptability of the products. Moreover, some lactic acid bacteria, besides producing lactic acid, also produce acetic acid and ethanol that may be responsible for an extreme acid odour, as reported before (Sinesio et al., 2000).

\section{Conclusions}

The manufacturer assigned a best before date of 45 days to the liver mortadella analysed; from a chemico-physical point of view, the product showed perceptible colour changes just after T45, independently from the storage temperature. The TBARS were always stable and always below the limit suggested. This confirmed an excellent oxidation stability of the product, with the absence of any signal

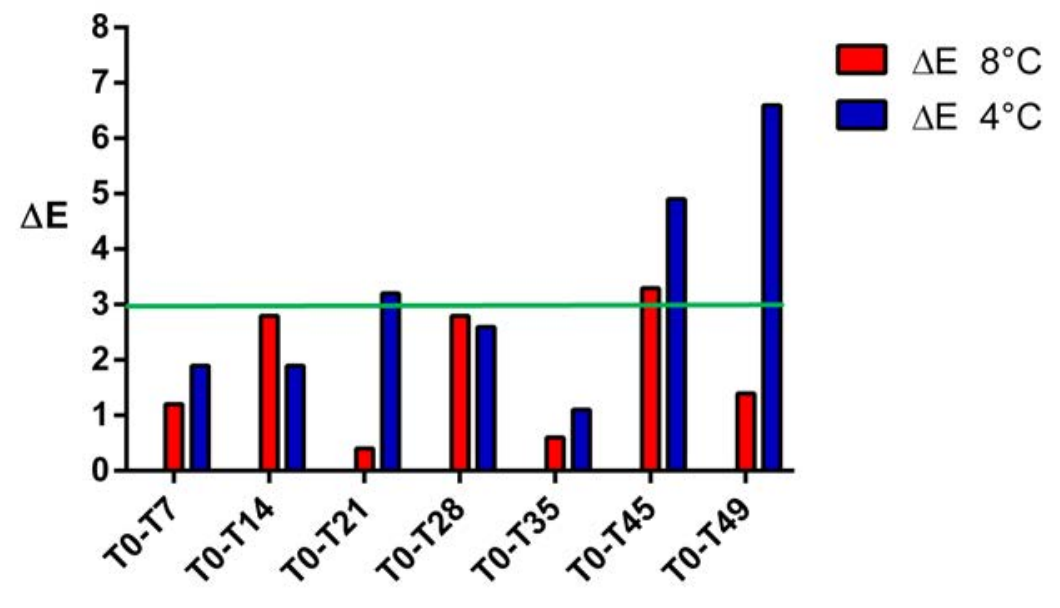

Figure 3. Colour parameters. 
of rancidity of the fatty component, an important parameter for preservation of the product and the suitability for consumption. The increase of $\mathrm{LAB}$, with the gradual lowering of the $\mathrm{pH}$ from $\mathrm{T} 14$, both at 4 and $8^{\circ} \mathrm{C}$, may have contributed to the development of sensory alterations determining an overall decrease of the quality; on the other hand, it may have had positive consequences in terms of antimicrobial effect against different pathogenic and spoilage microorganisms (such as L. monocytogenes, Enterobacteriaceae, Pseudomonas spp., Escherichia coli, coagulase positive staphylococci, sulphite-reducing clostridia, yeasts and mould), as already reported by Shelef and Potluri (1995). In fact, microbiological analyses showed unsatisfactory results from T14 (clearly from T35), due to the high microbial loads. Finally, the acceptability was found to decrease from T35 as a higher number of panellists rejected the product. As a consequence we feel, on the basis of our results (microbiological criteria, TBARS, LAB loads and colorimetric indexes), that it would be reasonable to attribute a shelf life below 35 days (reasonably around 28-30 days) to the product.

\section{References}

AFNOR, 1998. Detection of Listeria monocytogenes and Listeria spp. Association Francaise de Normalisation, La Plaine Saint-Denis, France.

AOAC, 1990. Official methods of analysis of the AOAC. $15^{\text {th }}$ ed. AOAC, Arlington, TX, USA.

Borch E, Kant-Muermans ML, Blixt Y, 1996. Bacterial spoilage of meat and cured meat products. Int J Food Microb 33:103-20.

Cantoni C, Bianchi MA, Beretta G, 1974. [Composizione chimica e valore nutritivo della mortadella di fegato]. [Article in Italian]. Ind Aliment 1974:132.

Estévez M, Ventanas J, Cava R, Puolanne E, 2004. Lipid and protein oxidation release of iron from heme molecule and colour deterioration during refrigeration storage of liver paté. Meat Sci 68:551-8.
European Commission, 2005. Commission Regulation of 15 November 2005 on microbiological criteria for foodstuffs, 2073/2005/EC. In: Official Journal, L 338, pp. 1-26, 22/12/2005.

ISO, 1998. Microbiology of food and animal feeding stuffs. Horizontal methods for the enumeration of enumeration of mesophilic lactic acid bacteria. ISO Norm 15214:1998. International Organization for Standardization, Geneva, Switzerland.

ISO, 1999. Microbiology of food and animal feeding stuff horizontal method for the detection and enumeration of coagulasepositive staphylococci. ISO Norm 6888:1999. International Organization for Standardization, Geneva, Switzerland.

ISO, 2001. ISO microbiology. General guidance for the detection of Beta-glucuronidasepositive Escherichia coli. Colony-count technique at 44 degrees $\mathrm{C}$ using 5-bromo4-chloro-3-indolyl beta-D-glucuronide. ISO Norm 16649-2:2001. International Organization for Standardization, Geneva, Switzerland.

ISO, 2003a. Microbiology of food and animal feeding stuffs. Horizontal method for the enumeration of microorganisms. Colonycount technique at $30^{\circ} \mathrm{C}$. ISO Norm 4833:2003. International Organization for Standardization, Geneva, Switzerland.

ISO, 2003b. Microbiology of food and animal feeding stuffs. Horizontal method for the enumeration of sulfite-reducing bacteria growing under anaerobic conditions. ISO Norm 15213:2003. International Organization for Standardization, Geneva, Switzerland.

ISO, 2004. Microbiology of food and animal feeding stuffs. Horizontal methods for the detection and enumeration of Enterobacteriaceae. Part 2: colony-count method. ISO Norm 21528-2:2004. International Organization for Standardization, Geneva, Switzerland.

ISO, 2012. Microbiology of food and animal feeding stuffs. Horizontal method for the detection of Salmonella spp. ISO Norm 6579:2012. International Organization for Standardization, Geneva, Switzerland.
Ke PJ, Cervantes E, Robles-Martínez C, 1984. Determination of thiobarbituric acid reactive substances TBARS in fish tissue by an improved distillation spectrophotometer meted. J Sci Food Agr 35:1248-54.

Korkeala H, Björkroth J, 1997. Microbiological spoilage and contamination of vacuumpackaged cooked sausages. J Food Protect 60:724-31.

Krol IB, 1966. Effect of heating on quality of meat products. $12^{\circ}$ Europ Meat Research Work, Finland.

Makela PM, Korkeala H, 1987. Lactobacillus contamination of cooked ring sausages at sausage processing plants. Int J Food Microbiol 5:323-30.

Mirna A, Hohmann K, 1969. [Uber den verbleib von nitrit in fleischwaren]. [Article in German]. Die Fleischwirtschaft 10:1361-6.

Paleari MA, Bersani C, Beretta G, 2005. Technology and shelf-life of "liver mortadella" and "sanguinacci". Ind Aliment 44:624-32.

Pearson D, 1973. Laboratory techniques in food analysis. Butterworths \& $\mathrm{Co}$ Publishers Ltd., London, UK.

Shelef LA, Potluri V, 1995. Behaviour of foodborne pathogens in cooked liver sausage containing lactate. Food Microbiol 12:2217.

Sinesio F, Di Natale C, Quaglia GB, Bucarelli FM, Moneta E, Macagnano A, Paolesse R, D'Amico A, 2000. Use of electronic nose and trained sensory panel in the evaluation of tomato quality. J Sci Food Agr 80:6371.

Villa R, 2010. [La mortadella di fegato. Un insaccato dal sapore deciso tipico dell'area padana occidentale tra l'Adda ed il Sesia]. [Article in Italian]. Premiata Salumeria Italiana 5:74.

von Holy A, Loete TE, Holzapfel WH, 1991. Quantification and characterization of microbial populations associated with spoiled vacuum-packed Vienna sausages. Food Microbiol 8:95-104. 